\title{
Genes determining dwarfism of watermelon Citrullus lanatus (Thunb.) Matsum. \& Nakai
}

\author{
Strygina K. ${ }^{1 *}$, Yanyshevskaya A. ${ }^{2}$, Elatskova A. ${ }^{3}$, Elatskov Yu. ${ }^{3}$, Tekhanovich G. ${ }^{3}$, \\ Khlestkina E. ${ }^{1}$ \\ ${ }^{1}$ Federal Research Center N.I. Vavilov All-Russian Institute of Plant Genetic Resources, St. Petersburg, \\ Russia \\ ${ }^{2}$ Pushkin Leningrad State University, St. Petersburg, Russia \\ ${ }^{3}$ Kuban Experiment Station of VIR, Krasnodar, Russia \\ * email: k.strygina@vir.nw.ru
}

Key words: Citrullus, Cucurbitaceae, dwarf genes, short vine, watermelon

Unlike many crops, the melon crops are characterized by the development of long vine that reaches 1.5 to $5 \mathrm{~m}$ in length, which makes harvesting difficult. Using methods of molecular genetics and marker-assisted selection, it is possible to create dwarf varieties growing in more northern latitudes, including beyond the Arctic Circle. The aim of this work is to identify and mark genes in the genome of watermelon Citrullus lanatus responsible for the formation of dwarf plant forms based on the unique collection of melon crops of the Federal Research Center N. I. Vavilov All-Russian Institute of Plant Genetic Resources (VIR). In genomes of Cucurbitaceae species, the search of homologous sequences of watermelon dwarf genes $d w-1$ (ABC transporter), $d s h$ (gibberellin 20-oxidase) and $d f$ (gibberellin 3-beta-hydroxylase) was performed. In genomes of Benincaseae species except for $C$. melo, one copy of $d w-1$ was identified, and in genomes of Cucurbiteae species and $C$. melo, two copies were found. The $d s h$ gene was identified in two copies in C. lanatus, in four copies in B. hispida, and in one copy in other analyzed species except for $C$. maxima and $C$. moschata, in which the gene was not identified. In C. lanatus, L. siceraria, and all Cucurbita species, and in B. hispida and all Cucumis species, two and three copies of $d f$ were found respectively. The allelic polymorphism was analyzed in genomes of VIR watermelon varieties. A total of 23 varieties and lines and 28 hybrids of $C$. lanatus were studied. A significant change in the motives, which could lead to changes in gene function, has been identified during sequencing in varieties with short and ultra-short vine.

Acknowledgments: The present study was supported by the VIR project No. 0481-20190001 . 